\title{
A POLÍTICA EDUCATIVA E SEUS EFEITOS NOS TEMPOS E ESPACOS ESCOLARES: A REINVENÇ̃̃O DO ENSINO MÉDIO INTERPRETADA PELOS JOVENS
}

\author{
Licinia Maria Correa* \\ Universidade Federal de Minas Gerais (UFMG), Belo Horizonte - MG, Brasil \\ Maria Amália de A. Cunha** \\ Universidade Federal de Minas Gerais (UFMG), Belo Horizonte - MG, Brasil
}

RESUMO: $\mathrm{O}$ artigo descreve o que pensam, sentem e experimentam os jovens do ensino médio da rede pública estadual de Minas Gerais quando confrontados com a implementação de uma política educativa que, alicerçada em uma reformulação curricular, modifica tempos e espaços escolares. Inicialmente, o trabalho contextualiza o Projeto Reinventando o Ensino Médio e a pesquisa. Na primeira seção, discutimos as questões que permeiam a implantação do projeto na rede pública estadual mineira, no período de 2012-2014. Na segunda seção, analisamos a percepção dos jovens que vivenciaram a política em sua dimensão prática, explorando uma metodologia do tipo qualitativo baseada nos grupos focais. As falas dos jovens são reveladoras de como tais políticas colocam os sujeitos para as quais elas são endereçadas em um lugar quase invisível. Por fim, na terceira seção, tecemos algumas ponderações acerca dos resultados da pesquisa.

Palavras-chave: Jovens. Ensino médio. Escola. Políticas Públicas.

EDUCATIONAL POLICIES AND THEIR EFFECTS ON SCHOOLINGSPACES AND TIMES: HIGHSCHOOL'S REINVENTION INTERPRETED BY YOUNGSTERS

ABSTRACT: In this paper, we aim to describe the feelings, thoughts, and experiences among young people in high schools of public State schools' network in Minas Gerais, Brazil, after implementation of new educational policies that reformulated curricula and modified schooling spaces and times. This work is organized in three sections. First, we discuss the political

\footnotetext{
"Doutora em Educação Escolar pela Universidade Estadual Paulista/Araraquara-SP. Professora Adjunta no Departamento de Ciências Aplicadas à Educação e no Mestrado Profissional Educação e Docência - Faculdade de Educação - UFMG. Membro do Observatório da Juventude da UFMG e do Grupo Interinstitucional Ensino Médio em Pesquisa. Email: < liciniacorrea@ufmg.br > .

"* Doutora em Educação pela Universidade Estadual de Campinas. Professora Associada do Departamento de Ciências Aplicadas à Educação e no Mestrado Profissional Educação e Docência- Faculdade de Educação- UFMG. Membro dos grupos de pesquisa Osfe (Observatório Sociológico Família e Escola) e do Nupede (Núcleo de Pesquisas em Desigualdades Escolares). Email: < amaliacunha@fae.ufmg.br >.
} 
context in which the project "Reinventing High School" emerged and was implemented in Minas Gerais' public schools between 2012 and 2014. In the second section, we analyse students' perceptions of such policies in their practical dimension, based on data obtained from focus groups. Their voices reveal that politics and policies often put in an invisible place the very subjects for which they are directed. Finally, in the third section, we make considerations and reflections about the results and impact of this research.

Keywords: Young people. High school. School. Public Policies.

\section{APRESENTAÇÃO}

O que pensam, sentem e experimentam os jovens do ensino médio da rede pública estadual de Minas Gerais quando afetados por uma política educativa que modifica os tempos e espaços escolares e propõe um novo currículo?

Essa interrogação nos fez percorrer um caminho analítico tendo como eixo as relações que os jovens estabelecem com a escola, demarcadas pela implementação de políticas públicas educacionais que visam a oferta de ensino de qualidade e o atendimento às demandas e expectativas de estudantes do ensino médio. Em um terreno mais circunscrito e limitado, encontramos esses sujeitos, em suas singularidades e em suas peculiares escolas. Noutro, amplo e abrangente, situamos o Projeto Reinventando o Ensino Médio, uma política pública que reorganiza o currículo do ensino médio nas escolas da rede pública estadual de Minas Gerais, no período de 2012-2014. ${ }^{1}$ Pensar a aplicação de uma política educacional a partir do olhar dos sujeitos para os quais ela se endereça constitui um campo fértil de análise para um tema que tem sido amplamente debatido e que está longe de chegar a um consenso.

Inicialmente, o artigo contextualiza a política e a pesquisa. Percorremos o curso de implantação de um projeto que altera o currículo, os tempos e os espaços escolares, entrecortado pelo nosso interesse investigativo: a pesquisa. Na primeira seção, focalizamos as questões estruturais que perpassam o ensino médio, posicionando o estado de Minas Gerais. Na segunda seção, analisamos a percepção dos jovens acerca da implantação desta política buscando compreender de que maneira seus percursos escolares foram afetados. Interessanos, sobretudo, saber como se manifestam quando instigados a falar de sua experiência de escolarização, dos saberes que circulam no espaço escolar, das expectativas que emergiram e ganharam forma na vivência de uma nova organização curricular. E, por fim, na terceira seção, apresentamos algumas ponderações que emergem da pesquisa. 


\section{0 PROJETO REINVENTANDO O ENSINO MÉDIO}

Alicerçada nos princípios de significação/identidade, empregabilidade e qualificação acadêmica, a Secretaria de Estado de Educação de Minas Gerais (SEE/MG) instituía para o ano letivo de 2013 uma nova organização curricular para o ensino médio regular, o Projeto Reinventando o Ensino Médio (REM). ${ }^{2}$ O REM foi implantado progressiva e gradativamente na rede estadual, iniciando em 11 escolas da Superintendência Regional Estadual (SRE) Metropolitana $\mathrm{C}^{3}$ com estudantes do primeiro ano do ensino médio. Em 2013, o REM foi estendido a 122 escolas distribuídas nas 47 SREs, sendo uma escola na sede e outra fora da circunscrição da sede (mas distando até $100 \mathrm{~km}$ desta). Em 2014, o REM foi universalizado nas 2.189 escolas de ensino médio da rede estadual. ${ }^{4}$

A determinação por reinventar o ensino médio apoiavase em quatro objetivos: 1) buscar a excelência no ensino e na aprendizagem; 2) garantir a especificidade da formação no ensino médio oferecido pela rede estadual mineira; 3) gerar competências e habilidades para a empregabilidade e 4) preparar os/as estudantes para o prosseguimento dos estudos.

Assegurando os 200 dias letivos, a nova organização curricular obedecia às Diretrizes Curriculares Nacionais para essa etapa da educação básica. Entretanto, a novidade do REM consistiu na ampliação da carga horária anual de 2500 para 3000 horas, distribuídas ao longo de três anos, destinadas ao desenvolvimento da formação geral e específica. A formação geral, cuja finalidade é, dentre outras, aprofundar e consolidar os conhecimentos apropriados no ensino fundamental estaria contemplada nos Conteúdos Básicos Comuns (CBCs). A formação específica, cujo escopo era ampliar o espectro de atuação e inserção profissional, consistiu na oferta de um acervo de áreas de empregabilidade que permitiriam aos estudantes construir seu próprio percurso acadêmico.

O desenho do REM contava com 18 áreas de empregabilidade que poderiam ser ampliadas. Dentre essas, as escolas ofertariam três áreas, referenciadas pelas demandas locais e interesses do alunado. Os jovens contariam com um instrumento de tutoria na escola e fariam um Seminário de Percurso Curricular, que lhes dariam condições de conhecer as potencialidades profissionais inerentes a tais áreas e favoreceria a construção de seu percurso curricular. Ao final, o percurso acadêmico do jovem desembocaria em dois eixos formativos com identidade clara: a formação pautada nos conteúdos curriculares e a formação sedimentada nas áreas de empregabilidade. 
A acomodação dessa organização curricular no cotidiano escolar dos jovens é o que pretendemos esmiuçar.

\section{OS ITINERÁRIOS DA PESQUISA}

A pesquisa consistiu no diagnóstico da implementação do REM na perspectiva dos sujeitos da escola: estudantes e docentes, tendo como base empírica 33 escolas da Região Metropolitana de Belo Horizonte- MG, divididas equitativamente entre as Superintendências Regionais (SREs) Metropolitanas A, B e C. O que caracteriza esse conjunto de escolas é o fato de serem as primeiras escolas inseridas no Projeto REM, consideradas, portanto, escolas piloto fase 1 (implantação) e fase 2 (expansão).

Conjugando instrumentos metodológicos quanti e qualitativos, ${ }^{5}$ examinamos as relações entre juventude e escola, a partir dos efeitos dessa nova organização curricular no cotidiano de jovens do ensino médio da Região Metropolitana de Belo Horizonte - Minas Gerais (RMBH-MG). A abordagem investigativa combinou instrumentos de análise contextual dos jovens - na condição de alunos - com instrumentos que propiciaram transitar pelo cotidiano escolar desses sujeitos, para compreender de que modo a implementação do REM afetava a vivência dos tempos e espaços escolares. Desse viés, a implementação do REM é o objeto heurístico sobre o qual convergem nossas reflexões.

$\mathrm{Na}$ primeira etapa investigativa, privilegiamos a análise bibliográfica assentada nas pesquisas que discutem a relação dos jovens com a escola, identidade e finalidade do ensino médio, estudos e dados censitários sobre o ensino médio em Minas Gerais e documentos oficiais, tais como as Diretrizes Curriculares Nacionais para o Ensino Médio. Percorremos ainda as resoluções e documentos oficiais do Governo do Estado de Minas Gerais e da Secretaria de Estado da Educação (SEE-MG) que tratavam da implementação do REM.

A leitura dos documentos que orientavam a implementação do REM trouxe informações relevantes para a tomada de decisões acerca dos procedimentos para a imersão no campo, especialmente porque essas leituras revelavam variações na maneira como se efetivava o projeto nas escolas piloto fase 1 e fase 2 , o que nos impeliu a estabelecer contato face a face com todos os gestores e/ou coordenadores do REM das 33 escolas. A análise prospectiva ocorreu a partir dessa primeira incursão nas escolas.

A formalização da pesquisa junto à SEE-MG e a entrevista com gestores e/ ou coordenadores do REM integram e finalizam essa primeira etapa. Cabe ressaltar que esse contato foi primordial para 
apreender as intercorrências na operacionalização do REM e para aproximarmo-nos de cada escola em seu contexto mais amplo.

$\mathrm{Na}$ segunda etapa, aplicamos questionários aos jovens do segundo e terceiro anos nas 21 escolas. A seleção das escolas considerou critérios que serão descritos ulteriormente. Foram aplicados 3108 questionários, distribuídos nas SREs Metropolitanas A, B e C. No diálogo com os jovens sobre o cotidiano escolar, os grupos focais foram a maneira escolhida para alcançar os sujeitos, as interpretações construídas e compartilhadas coletivamente sobre a vivência da política.

Quanto aos docentes, optamos por duas escolas que pudessem nos fornecer uma leitura aproximativa do processo de implantação do REM nas fases piloto e de expansão. Realizamos entrevistas compreensivas com docentes, coordenadores e professores orientadores do REM, bem como com outros sujeitos citados pelos mesmos.

Neste artigo, a combinação das metodologias não foi exaustivamente explorada. Tampouco perquirimos os dados coletados junto aos docentes e uma rede de informantes por eles citados, ponderando os limites desse quadro analítico. Optamos por oferecer aqui um retrato geral dos jovens pesquisados, do ponto de vista da sua morfologia social: idade, gênero, pertencimento étnico-racial e distorção idade-série. Analisamos os grupos focais realizados em três escolas, ${ }^{6}$ evocando as questões que emergiram dos diálogos com/ entre os jovens que vivenciaram o REM em sua fase de expansão, fronteadas por nossas reflexões e aproximações teóricas.

\section{AS ESCOLAS PESQUISADAS E OS EMBARAÇOS ESTRUTURAIS DA ADESÃO AO REM}

A constante insistência nas fases de implementação do REM não se limita à óbvia constatação de que uma política não se instala no vazio. Sua perenidade, sua existência e resistência são um reflexo de condições objetivas: os sujeitos e suas demandas, as condições estruturais de funcionamento, os tempos e espaços em que se estabelece. Definidos os sujeitos, buscamos identificar as características do processo de implementação do REM que pudessem parametrizar a escolha de determinadas escolas em um universo de 33 estabelecimentos de ensino. Esse cenário só foi possível visibilizar após a consolidação das visitas às escolas.

Inequivocamente, aleitura dos documentosoficiais, as conversas formais e informais com gestores, coordenadores do REM e outros informantes das escolas, revelaram peculiaridades e discrepâncias nas formas de implementação, adesão e operacionalização do projeto 
nas escolas. Tais discrepâncias se expressam i) no território, ou seja, no contexto socioespacial em que se localizava cada estabelecimento de ensino; ii) nas fases de implementação do projeto nas escolas, que denominamos aqui "tempo de adesão ao REM" e iii) na oferta das áreas de empregabilidade, que eram o cerne da proposta de reorganização curricular.

\section{CONTEXTO SOCIOESPACIAL DA ESCOLA}

Para tratar do contexto socioespacial das escolas, partimos do pressuposto de que as escolas são parte de (e também constituem) um território, cuja complexidade não se restringe aos limites geográficos. Escolas são contextos sociais demarcados por mecanismos que separam territorialmente classes e grupos sociais. Ao incorporar o fenômeno de organização social do território em relação com as desigualdades escolares nas análises dos dados educacionais, destacamos um conjunto de pesquisas que evidenciam como as desigualdades educacionais podem estar ainda profundamente enraizadas na complexa dinâmica do espaço vivido, transmutando-se nas desigualdades socioespaciais de acesso à escola. (SALATA, 2010; ALVES, FRANCO E RIBEIRO, 2012; KOLINSKY E ALVES, 2012; BATISTA E CARVALHO-SILVA, 2013).

Os jovens, sujeitos da pesquisa, sabiam indubitavelmente que o lugar onde viviam, a escola onde estudavam eram fontes de limitação ou de ampliação das oportunidades. As quebradas, os pedaços, os bairros, lugares nos quais constroem e significam seus modos de existir, circunscrevem suas escolhas. Assim, tivemos o cuidado de pensar, a partir das combinações territoriais que tínhamos à nossa disposição, uma variação demográfica entre as escolas pesquisadas que pudesse explicitar a dimensão territorial como um aspecto condicionante na efetivação de uma política educativa.

Priorizamos uma representatividade dentre o conjunto das cidades que compõem a RMBH, que vão das cidades consideradas polos industriais (Contagem e Betim), a outras consideradas de pequeno porte e com características marcadamente rurais. Em segundo lugar, optamos por incluir uma escola que se situasse próxima aos terminais de transporte público (ônibus e metrô), que são altamente convenientes aos jovens alunos trabalhadores, supondo as dificuldades para conjugarem local de moradia, escola e local de trabalho. Outro aspecto foi a localização territorial e o modelo de segregação centro-periferia, associados ao prestígio da escola. 


\section{TEMPO DE ADESÃO AO REM}

A cronologia de implantação do REM, que vai da implementação do Projeto Piloto à sua universalização, passando pela fase de expansão, é um elemento fundamental na interpretação dos dados coletados nessa pesquisa. O que intitulamos "tempo de adesão ao REM" designa um intervalo temporal na efetivação do projeto que distingue as escolas entre si e assinala a política educativa não somente como algo ou uma ação que se executa, mas como uma experiência vivida por cada sujeito em cada estabelecimento de ensino. Um tempo que se define entre o deliberado e o factível.

Este aspecto da política educacional é bastante complexo, uma vez que, de acordo com Lessard e Carpentier (2016), tendemos a subestimar a aplicação da política na prática, do ponto de vista dos sujeitos aos quais elas se dirigem. Isto porque, tradicionalmente, segundo os autores, o campo de análise das políticas educativas esteve voltado para uma visão funcionalista e racionalista de atividade do sistema político, seguindo uma sequência preconizada por um problema, a formulação de uma política específica, decisão, aplicação na prática e avaliação.

A implementação de um Projeto da envergadura do REM, requeria espaços físicos, recursos humanos, equipamentos tecnológicos e recursos financeiros que pudessem ser gerenciados autonomamente pelas escolas para a aquisição de grande volume de material de consumo e material permanente. Sob o título "Implementação do Reinventando: do projeto piloto à expansão", publicado em um dos cadernos do Reinventando o Ensino Médio, a Secretaria de Estado da Educação denominou "princípio metodológico", os aspectos que consistiam no patamar mínimo necessário à execução do projeto nas escolas.

Esse documento continha, portanto, as informações relativas à infraestrutura, entendida como o conjunto de elementos que possibilitassem a realização da atividade educativa. As escolas do REM deveriam possuir laboratórios, equipamentos de informática de ponta, reforma e ampliação da rede lógica e recursos de multimídia, a fim de que pudessem viabilizar o uso de tecnologias inovadoras no campo da educação.

Além dos equipamentos e da criação de espaços específicos, o REM previa recursos humanos que atuariam especificamente nas áreas de empregabilidade. Além dos docentes (inicialmente apenas professores efetivos), a equipe responsável pelo projeto nas escolas contaria com um professor orientador por área de empregabilidade e um coordenador geral do REM em cada escola e em cada turno. Esses últimos estariam em contato direto com consultores, no caso, docentes 
das universidades públicas, que colaborariam na produção de materiais didáticos a serem disponibilizados por meios virtuais a partir de 2013.

Ainda pautada no princípio metodológico, havia a previsão do repasse de recursos financeiros que estruturariam, sobretudo, as atividades práticas, visitas técnicas empreendidas na fase de implantação do Projeto nas onze escolas do Vetor Norte, estendendo-se para as escolas da fase de expansão. Por fim, um aspecto não previsto, mas que afetaria substantivamente as ações do REM, foi o aumento no consumo da merenda escolar, dado que os estudantes permaneciam na escola até o final do sexto horário, parte desses moravam distante das escolas e outro grupo iria diretamente para o trabalho.

\section{6. ÁREAS DE EMPREGABILIDADE}

Opondo-se à excessiva desvinculação da escola ao mundo do trabalho, à falta de uma sólida preparação para a inserção profissional e à rigidez curricular, o REM ofereceria “... novas competências e habilidades de maneira a permitir que o aluno egresso deste nível de ensino esteja mais preparado para os desafios atinentes ao mercado de trabalho." (SEE-MG, p.21). Tanto no documento que apresenta o projeto, quanto na Resolução 2.486, da SEE-MG, a empregabilidade ${ }^{1}$ ancorava-se na possibilidade de desenvolver nos jovens as habilidades e atitudes, ou seja, as competências que, no mundo globalizado, permitiriam ao jovem ocupar "postos de trabalho múltiplos e inespecíficos" (sic). A escola do REM assume, com isso, a responsabilidade de preparar o jovem não somente para buscar trabalho, como também mantê-lo.

Era com esse espírito que o desenho do REM previa inicialmente 18 áreas de empregabilidade. A escolha das áreas era uma prerrogativa dos jovens alunos que manifestariam seus interesses a partir de opções ofertadas pelas escolas. Após ampla discussão, momentos de diálogo com os (as) estudantes e estudo das demandas territoriais, as 11 escolas da SRE Metropolitana $C$ optaram por três áreas: Turismo, Tecnologia da Informação e Comunicação Aplicada. A oferta das mesmas áreas pelo conjunto das escolas advinha da preocupação dos gestores com a obrigatoriedade dos jovens concluírem o percurso na área escolhida, caso mudassem de escola.

Este mesmo caminho não se desenhou nas escolas que fizeram a adesão em 2013. Ao indagar aos gestores o porquê da oferta das mesmas áreas de empregabilidade escolhidas pelas 11 primeiras escolas, constatamos que os gestores seguiram o fluxo das escolhas 
feitas anteriormente, independentemente das demandas territoriais, dos interesses e necessidades dos jovens. $\mathrm{Na}$ entrevista com gestores, estes foram unânimes em dizer que não tiveram tempo hábil para realizar consultas aos estudantes, debates com a comunidade ou reuniões com sua equipe. Os gestores foram "informados" da adesão e da mesma forma, repassaram as informações aos seus professores. Os alunos, por sua vez, souberam do REM no ato da matrícula e, naquele mesmo instante, deveriam escolher dentre as áreas já definidas, sem saber o que elegiam e porque faziam tal escolha.

\subsection{O QUE REINVENTAR QUANDO SE TRATA DE ENSINO MÉDIO: POLÍtICAS PÚBLICAS EDUCACIONAIS E O CONTEXTO DE MINAS GERAIS}

A universalização do acesso à escola tornou-se realidade para as crianças brasileiras matriculadas no ensino fundamental. Atualmente, essa etapa do ensino abarca a totalidade das matrículas, ainda que persista o problema da qualidade, explicitados nos indicadores de desempenho dos programas nacionais e internacionais de avaliação de desempenho. É, portanto, no ensino médio, etapa final da educação básica, que está o gargalo e é para lá que se voltam os olhares e as políticas educacionais na última década.

Os estados brasileiros, responsáveis diretos pela oferta do ensino médio e, paulatinamente, transferindo aos municípios a responsabilidade e a prerrogativa da oferta do ensino fundamental, mobilizam-se para o enfrentamento da problemática que circunda essa etapa da educação básica. Atualmente, 68,1\% das escolas de ensino médio são estaduais e $29,2 \%$ são privadas. A União e os municípios participam com 1,8\% e 0,9\% de escolas, respectivamente. De 8,1 milhões de matrículas no ensino médio, a rede pública concentra 96,9\% deste percentual e dessas, 6,9 milhões estão alocadas na rede estadual, ou seja, 84,8\% do total das matrículas. (INEP, 2016).

O Estado de Minas Gerais concentra o segundo maior número de matrículas da federação e apresenta resultados ${ }^{8}$ de desempenho abaixo das metas desde 2011. O enfrentamento dessas questões justifica o seu pioneirismo na implementação de programas e projetos cujo escopo é oferecer um ensino médio que atenda às exigências da sociedade, que seja capaz de afrontar o insuficiente desempenho nas avaliações nacionais e internacionais, o problema do abandono, evasão escolar e a distorção idade-série.

Iniciativas equivalentes aos programas empreendidos pelo governo federal são exemplos dessa anuência do governo estadual mineiro às iniciativas do governo federal. Em 2006, o Novo Plano 
Curricular do Ensino Médio já trazia perspectivas de um novo currículo para a rede estadual, intitulado Ciclo Básico Comum (CBC), com características consonantes àquelas preconizadas pela LDBEN 9394/96 e reafirmadas no documento oficial que apresenta a proposta. Experiências como o ensino médio integrado ou programas de profissionalização simultânea, tal qual o Programa de Educação Profissional (PEP), eram algumas das ações preexistentes ao REM.

Por intermédio da Resolução SEE $\backslash M G$ n. 2.030, de 25 de janeiro de 2012, o REM passa a figurar como diretriz políticopedagógica do ensino médio e apresenta-se como possibilidade de "ressignificação da escola pública". Os princípios da significação/ identidade, empregabilidade e qualificação acadêmica, que nortearam o projeto, ofereceria aos estudantes "percursos curriculares alternativos, flexibilidade, uso das novas tecnologias de ensino/ aprendizagem, atividades interdisciplinares e instrumentos formativos extraescolares". (SEE-MG, 2012, p.11).

Embora o REM tenha sido um programa educacional desafiador, sobretudo ao postular uma equilibrada aproximação entre educação, empregabilidade e cidadania, é imprescindível perguntar pelos efeitos de sua idealização e posterior implementação na perspectiva dos sujeitos mais diretamente implicados nas mudanças que se sucederam, os jovens.

Lessard e Carpentier (2016) evidenciam o quão difícil é compreender um empreendimento de renovação curricular ou de transformação das práticas pedagógicas dos professores e alunos, bem como dimensionar o sentido da política educativa para os sujeitos. Tal complexidade suscita indagar aos jovens pelos significados do REM em suas experiências de escolarização. São elas e eles que vivenciam a escola para além da aquisição de conteúdos e colocam sob suspeição o modelo escolar vigente.

É nessa fissura entre o pretendido e o sucedido que se insere a contribuição da pesquisa, ou seja, no entremeio de uma política educacional e sua repercussão na vida dos sujeitos. Nossas escutas foram permeadas por reflexões acerca da condição juvenil, da relação dos jovens com a escola e com os saberes que por ali circulam. Analisamos o impacto do REM sobre os tempos da vida juvenil enredados no tempo-espaço da rotina pedagógica e do trabalho docente. E essas dinâmicas temporais - tanto dos jovens quanto das escolas foram ainda capturadas pelos condicionantes estruturais da implementação do REM. Os efeitos desses atrelamentos foram experimentados e descritos pelos jovens. 


\subsection{A POLÍTICA E SEUS EFEITOS: A REINVENÇ̃̃O DO ENSINO MÉDIO INTERPRETADA PELOS JOVENS}

Abad (2003), Abramo (2005), Margulis e Urresti (2002) são autores que tematizam a multidimensionalidade da juventude. A concepção de juventude como uma etapa vital entre a infância e a maturidade, marcada pela transição ao mundo adulto é uma primeira forma de aproximação conceitual ancorada na psicologia. Para a sociologia, a juventude "[...] têm se convertido numa categoria social, interclassista e comum a ambos os sexos, definida por uma condição específica que demarca interesses e necessidades próprias, desvinculadas da ideia de transição e suas instituições responsáveis" (ABAD, 2003, p. 23).

Essa noção de juventude permite uma abordagem conceitual em que a situação na qual cada sujeito experimenta a juventude é o fator de compreensão das diferenças e desigualdades que atravessam a condição juvenil. Se fazer parte de um grupo social, de uma coorte geracional se definem como uma condição; a classe social, o pertencimento étnico-racial, a segmentação territorial, os condicionantes de gênero e sexualidade definem a singularidade da vida juvenil. Nesses modos de vida específicos os jovens se situam de maneira diversa e é interrogando suas variadas formas de inserção na vida pessoal e social que podemos fazer uma leitura mais ou menos coerente desta paradoxal juventude.

Jovens em suas singularidades e juventudes em sua pluralidade. Os sujeitos dessa pesquisa trazem para a escola um conjunto de experiências sociais. É na experiência vivida nos mais variados espaços que os jovens articulam sua própria cultura, sendo impossível separar o sujeito de suas práticas culturais, de sua história pessoal e de suas marcas sociais. Não são uma coisa ou outra, jovem ou aluno, mas revelam-se na pluralidade de seus pertencimentos:

Fabiano: (...) então a juventude no Brasil ela é muito múltipla, sabe? Se você for num país mais desenvolvido, a juventude geralmente ela é mais homogênea, aqui ela é um pouco diferente, tem muitos tipos de jovens, tanto é que os conceitos de juventude tão modificando, por quê? Como o nosso maior amparo é a família, é, o que que acontece, muitos jovens aqui vão ter um pensamento diferente, uma opinião diferente, então no Brasil é, por exemplo, as pesquisas, muitas pesquisas abordam que o jovem não gosta de política ou que ele não gosta de estudar, por exemplo, isso pode ser alguma parte dos jovens, já a outra parte pode gostar de política e sim pode gostar de estudar porque é muito múltiplo. Um mora no Belvedere, o outro mora na Serra, o outro morou na Biquinha, sei lá... (Grupo Focal Escola B).

Suas vivências anteriores atravessam os portões, os muros e adentram o cotidiano escolar. Somente considerando a dimensão da experiência vivida é que o cotidiano se torna espaço e tempo 
significativos. É essa experiência que faz dos jovens sujeitos socioculturais, pois se constitui a matéria-prima por meio da qual articulam sua própria cultura. (DAYRELL, 2001).

Logo, explicitar o perfil dos sujeitos dessa pesquisa é admitir os limites de nossas análises. Os alunos com os quais tivemos contato estavam entre os 8,1 milhões de jovens matriculados no ensino médio regular (INEP, 2016). No estado de Minas Gerais, eram 729.524 mil. Desses, nosso universo restringiu-se aos 3.108 alunos da RMBH que responderam ao questionário e aos 80 que participaram dos grupos focais. Esses jovens estavam matriculados nos segundos e terceiros anos, em acordo com o recorte da pesquisa: o período de implantação do REM. Dentre esses jovens, $56,5 \%$ eram do sexo feminino e $43,5 \%$ do sexo masculino. No momento da pesquisa 32,8\% tinham 17 anos, 32,4\% tinham 18 anos e 12,9\% tinham 19 anos. Em relação ao pertencimento étnico racial, $52,2 \%$ se autodeclararam pardos, $26,3 \%$ brancos e $16,3 \%$ se autodeclararam pretos.

Com relação à divisão por ano em curso no ensino médio, $47,7 \%$ estavam no segundo ano e $42,7 \%$ no terceiro ano deste segmento. No que diz respeito à trajetória escolar, 34,7\% dos alunos haviam interrompido os estudos. Desses, 48, 4\% interromperam no decorrer do ensino médio, $28,9 \%$ nos anos finais do ensino fundamental e $21,1 \%$ nos anos iniciais.

A escolha dos jovens como interlocutores foi orientada pela compreensão de que eles têm uma aguda percepção das mudanças estruturais que afetam a sua relação com a chamada "caixa preta do universo escolar": o currículo, a relação com os professores, com os colegas, com o aprender e com o saber.

\section{OS ESPACִOS DO SABER E OS SUJEITOS DO APRENDER}

Os estudos de Charlot $(2000,2001)$ oferecem um marco teórico importante para a compreensão das relações que os jovens instituem com a escola. Em sua dimensão de sujeitos cognitivos, os jovens estabelecem relações com o conhecimento, conferem sentidos para seus aprendizados e se mobilizam em direção ao saber, tal como revelam os excertos a seguir:

Patrícia: Não existe aquela pessoa que fala assim: "eu não sou mais estudante", todo mundo tá sempre aprendendo, todo mundo tá sempre ensinando, a vida é assim, não existe de falar isso: "ah, eu vou sair da escola, não vou estudar mais". Você vai estudar sim, ou você vai fazer uma faculdade ou você vai fazer um curso ou você vai aprender no trabalho, você tá ali estudando no seu trabalho para aprender uma função, sempre tá estudando (Grupo Focal Escola A). 
Tal como explicita Patrícia, são muitos os lugares de aprender. E aprender, para os jovens, diz muito sobre as formas de interação que experimentam com os outros. A escola, sublinha Sposito (2005), ao lado da família, é legitimada pelos jovens como instituição fundamental em suas experiências de socialização. A ênfase na condição de aluno ou estudante não deve, contudo, ignorar outras dimensões da sociabilidade juvenil com as quais constroem suas experiências escolares.

As vivências escolares, mas não necessariamente didáticopedagógicas, informam que a sociabilidade tem um caráter cognitivo pouco reconhecido. Aprende-se com os amigos. Aprende-se a conviver com e através dos pares.

Marcelo: Os amigos eu acho importante e eu gosto muito dessa coisa de escola (...) isso é bom porque na escola você tá aprendendo ainda e se a gente não tivesse essa fase aqui na escola, a gente chegaria no trabalho e se não soubesse lidar com as personalidades diferentes das nossas, a gente poderia ter um problema muito maior, na escola a gente aprende a lidar e ter mais consciência (Grupo Focal Escola B).

Ao discutir a relação dos jovens com o saber, Charlot (2001) define este sujeito social abstratamente chamado de aluno como um ser humano aberto ao mundo, portador de desejos, carregando em si as marcas da individualidade. Nascem e crescem em uma família, que ocupam uma determinada posição em um espaço social e estão inscritos em determinadas formas de relações sociais.

Flávia: As pessoas, tem momento que a gente tem que aprender a lidar com o diferente, porque dentro da tua casa, são aquelas regras que você desde pequeno tá acostumado, é com a mãe virando e falando, todo dia antes do almoço: você vai lá e vai lavar as vasilhas ou já é, entendeu? (Grupo Focal Escola B).

Em A família como espelho, Sarti (1996) declara que família é uma linguagem por meio da qual os pobres traduzem o mundo. Toda possibilidade de negociação e de atuação no mundo passa por caminhos em que seja possível falar esta linguagem. Negar sua importância como tradução das relações sociais é falar um idioma incompreensível. A noção de família define-se em torno de um eixo moral. Existe um princípio de obrigação moral que fundamenta a família, estruturando suas relações. São as redes de obrigações que delimitam os vínculos e a extensão da família entre os pobres. Dispor-se a estas obrigações morais define o pertencimento ao grupo familiar. A noção de obrigação sobrepõe-se aos laços de sangue. Nas relações familiares as obrigações não se escolhem. Em outros grupos, são seletivas. 


\section{OS JOVENS, A EXPERIÊNCIA ESCOLAR E OS PROJETOS DE FUTURO}

Quando analisam a subjetividade da experiência escolar juvenil, Dubet e Martucelli (1996) ressaltam que os jovens entram na cena social instados a explicar e a equacionar sua relação com o mundo. O reconhecimento da juventude como um grupo social ou como uma experiência de massa na sociedade moderna confere a estes indivíduos uma "relativa autonomia" na maneira de gerir a vida.

Gerir a vida e gerir também o tempo. O tempo, como aponta Elias (1998) é uma relação e não um fluxo contínuo. É o elemento de representação dos diversos processos específicos que procuramos marcar com o relógio ou o calendário. O tempo é social porque, antes de tudo, expressa um determinado modo de relação sujeito-objeto. É um instrumento de regulação e ordenação das atividades sociais.

Se nas sociedades modernas a experiência do tempo se desenvolve como tempo de formação, tempo produtivo e tempo livre, os jovens (até mesmo pela sua capacidade de desafiar e apropriar-se das configurações temporais hodiernas) são mais diretamente afetados por essa urgência em temporalizar suas biografias. Nas conversas informais e nos registros dos grupos focais essa necessidade de dar conta do tempo em que vivem como jovens e como estudantes, nos pareceu sensivelmente pungente. Cada ano do ensino médio, o primeiro - o segundo - o terceiro são vividos numa forma de angústia de quem vê o tempo escorrendo. Mas tempo de quê? Tempo para quê?

Davi: Será se é isso... Aí entra a incerteza. "Será que é isso mesmo que eu quero para minha vida?” Não sei se sou só eu, mas quando eu entrei no primeiro ano, era uma das primeiras coisas que vinha na minha cabeça. E agora que eu tô me tornando um adulto que vou começar a fazer as minhas próprias escolhas e que é agora que eu tenho realmente que fazer cursos que vão me beneficiar em coisas que eu quero seguir, é... escolher a minha profissão certa, se eu vou ser feliz fazendo aquilo, então... agora que tô no segundo ano, eu sempre... no meu caso, eu sempre pensei em ser jornalista, desde os meus dezessete anos eu tenho essa... essa coisa, só que se nessa hora eu descobri que jornalismo não é uma coisa que eu realmente quero fazer. Só que aí tá a pergunta que me deixa louco, assim, acho que todos os jovens, que é: o que eu quero fazer? Eu decidi o que eu não quero fazer mais, mas eu não sei o que que eu quero fazer agora. E começa toda a preparação de ENEM, de... olhar a faculdade que vai ser apta para mim, lugares que... vão recorrer nisso, se vou para uma escola interna, se vou ficar indo em casa mesmo na faculdade com 
campus, sem campus, é... o que que eu tô fazendo... E se eu começar a trabalhar, como é que eu vou conciliar isso e escola... então tem toda uma preparação que você tem que se preparar, mas ao mesmo tempo você... cê não sabe por onde começar isso. (Grupo focal Escola C)

No caso dos sujeitos dessa pesquisa, ser jovem e ser aluno do ensino médio implica um duplo movimento. Um movimento que os impele a viver a juventude, esse tempo singular de experimentar o mundo, de constituir suas identidades individuais e coletivas. Outro movimento que os impele a viver o tempo de formação que, em nossa sociedade, coincide com o tempo instituído pela escola.

Se, de um lado, ser jovem é sair, curtir os amigos, extravasar e indagar-se sobre o que querem ser; de outro, ser estudante é ter a responsabilidade de ir à escola, participar das aulas, estudar, perguntarse sobre o que querem fazer. Os jovens confirmam, portanto, as representações compartilhadas comumente entre nós, tais como ser jovem é “... sempre tá aberto a novas experiências, vivendo coisas novas, tudo novo..." e também atestam que nesse momento são instados a fazer escolhas, a tomar decisões: “... tempo de correr atrás, de plantar pra poder colher. Estudar, divertir, pesquisar, aprender, pra mim, ser estudante é isso". O diálogo abaixo é ilustrativo de como o tempo da vida juvenil é demarcado pela necessidade de delinear projetos, de prospectar o futuro. E é nessa fissura que indicam o lugar dos processos de escolarização.

Davi: No caso é... exemplo: "O que eu vou ser feliz fazendo?”, "O que que eu vou querer fazer no futuro?” Se eu tenho aptidão para isso, se eu posso correr atrás se eu não tiver. É você descobrir da onde você quer ir e se você tem vontade, se é capaz para conseguir chegar aonde você quer ir.

Mediadora: Hum. Essa coisa do futuro... tá muito na cabeça de vocês?

Davi: Totalmente...

Henrique: Ainda mais agora.

Mediadora: Ainda mais agora...

Henrique: Porque agora sou um homem formado, no segundo, ano que vem é o último. Depois você quer saber o que que você quer fazer, se alguém tem vontade de fazer faculdade, que faculdade vai querer fazer. É...

Davi: É difícil... Quem tá no terceiro que sabe.

Henrique: Quem tá no terceiro que sabe. Porque até o segundo ano você tem um foco. Quando você tá no terceiro que você vê que já tá acabando, você fala assim: "Meu Deus..." (Grupo Focal Escola C)

Manifesta-se um desejo de viver a juventude e um reconhecimento do lugar da escola naquilo que concerne à vida estudantil. Essa 
complexidade que nos afeta cotidianamente é sentida pelos jovens com maior intensidade. É que o tempo da vida juvenil - tempo de tomada de decisões, de definir limites, fazer escolhas e abrir-se ao futuro, não é mais um horizonte no qual devem ordenar suas escolhas e comportamentos, erguer pontos de referência para suas ações -, é o irremediável presente. $\mathrm{Na}$ sociedade do risco, da imprevisibilidade, o tempo juvenil é um tempo de indeterminação e de individualização das biografias. E os processos de escolarização se inscrevem nessa dinâmica temporal. Na escola, aprendese para a vida e para levar adiante projetos, perspectivas de futuro. $\mathrm{O}$ ENEM, os concursos públicos, o trabalho, no presente e no futuro.

Ricardo: Muita coisa, tipo, o que eu quero falar é que tem coisa que você não vai usar pra vida de verdade, por exemplo, o x de quadrado de triângulo, ou de alguma coisa... Eu não vou usar isso! O que eu vou realmente usar eu já aprendi, que é fundamental que é somar, subtrair, dividir e multiplicar, o que mais eu vou usar? (Grupo Focal Escola C)

Os jovens, especialmente aqueles oriundos das camadas populares, experimentam nas condições estruturais da vida juvenil as vicissitudes de uma escolarização que lhes é necessária e ilusória. Contudo, pelas suas formas de resistência e pela sua capacidade de desafiar a lógica do sistema, estes sujeitos desenvolvem estratégias que lhes permitem construir a experiência escolar, ora apropriandose do que lhes parece conveniente, ora esquivando-se daquilo que lhes parece inadequado.

Fabiano: Ô Ricardo, é importante saber que a gente usa sim, sabe? (...) se ele - professor - conseguir contextualizar essa matéria, eu acho que a gente vai ter vontade de aprender, porque realmente é o que ele entende. Oh, eu não vou usar isso nunca na minha vida então eu não quero aprender não, é só pra passar de ano? (Grupo Focal Escola B)

A experiência de escolarizar-se consiste, dentre outros aspectos, em pensar os saberes que lhes interessam, carregados de sentido, mas pensar também que há um conjunto de saberes essencialmente instrumentais, que podem levar a algum lugar. Um posto de trabalho, a aprovação no ENEM ou um curso superior. Mas o ENEM não é um exame que avalia somente os conteúdos. Ou melhor, os conteúdos da prova são carregados de sentidos. Sentidos que estão lá onde está o aprendizado da convivência. Sentidos que estão no conhecimento mais amplo do mundo que os cerca.

Marlice: ... aí você chega na prova do ENEM que é pra avaliar, chega lá te pega, por quê? Porque o professor, ele te falou assim, é A, B, C, aí chega lá na prova, tem A, B e C, mas tá no meio de um monte de outras coisas que é uma questão 
mais social, do que tá realmente acontecendo (...) porque não é só uma questão de faculdade e de emprego, é questão mesmo de convivência, em todos os sentidos. (Grupo Focal Escola B).

Esses diálogos ressaltam a importância da escola na orientação das possíveis escolhas que serão feitas pelos jovens. Confirmam a necessidade do conhecimento escolar e das noções culturais que a escola transmite para conseguirem vislumbrar perspectivas, delinear projetos.

Amanda: O que eu mais gosto na escola é o conhecimento adquirido só que isso tá péssimo. Aqui mesmo na escola tem sido um pouco decepcionante pra mim, tem professores muito ruins que incentivam a gente a não seguir em frente, sabe? Dizendo que a gente é analfabeto, que a gente não vai chegar a lugar nenhum. Isso aí é decepcionante, né? Não é só a estrutura, mas ele não tá incentivando a gente pro nosso futuro! (Grupo Focal Escola A).

Os jovens sabem que a escola deveria conferir-lhes algo que não se perde, que não pode ser tomado, porque uma vez apropriado será exclusivamente deles: o saber, o conhecimento. E nos dizem ainda que tipo de saberes é necessário à sua vida. Negar o acesso ao conhecimento é deixar-lhes à margem, impedi-los de conhecer e desenvolver suas próprias habilidades, destituir-lhes de seus sonhos.

É como se tudo (ou quase tudo) dependesse das relações que se constroem no ambiente escolar e da relação que os jovens estabelecem com o saber. A referência às disciplinas escolares, à postura docente informa que os jovens agem no mundo e sobre ele, trazem consigo o saber como necessidade de aprender e como uma presença no mundo dos objetos, pessoas, lugares. Ao falar dos processos de escolarização, dos mais variados vínculos estabelecidos com a escola, os jovens atestam que ainda depositam na escolarização suas expectativas de mobilidade social.

As expectativas de mobilidade social, via escolarização, são um velho e recorrente tema que permeia a relação dos jovens com a escola e, junto a outros fatores, contribui para o modo como se fazem alunos, ou seja, como vivenciam o cotidiano escolar. Os jovens estudantes principalmente os oriundos das camadas populares - são otimistas, acreditam na escola, no potencial mobilizador da escolarização e vivem a escola como lócus de formação e de socialização.

\section{A DOCÊNCIA INTERPRETADA PELOS JOVENS}

Os jovens falam das relações que tecem com os docentes. Interpretam o exercício da docência de diferentes modos. Num dado momento, falam de uma experiência do aprender em que a hierarquia 
é móvel porque é definida em um jogo de posições ocupadas por aqueles que dispõem do saber. A relação ensinar-aprender é, positivamente, flutuante. Descrevem uma relação pedagógica em que alunos aprendem com seus professores, esses com seus alunos e aprende-se com o grupo de pares, com os outros.

Lucas: (...) mas tipo assim, eu discordo um tiquinho porque pensa comigo, a gente não só aprende, a gente transmite pro professor, sabe? O professor aprende muito com a gente, a gente troca muita experiência com o professor, com aluno mesmo, a gente quando faz trabalho na casa do outro, a gente troca muita experiência, entendeu? Entre os alunos, entre os professores mesmo, eles tendem a aprender, a desenvolver com a gente que é aluno (Grupo Focal Escola A).

Em outro momento, falam da docência no singular. De uma autoridade docente que se revela na capacidade de mediar a relação com o saber, na capacidade de conectar-se com o outro. Há o professor que sabe ensinar, mas não sabe o que ensina. Professor que sabe o que ensina, mas não sabe ensinar.

Adriana: Eu queria deixar uma coisa clara em relação a esse professor, igual ela falou, não é que ele é um professor ruim, né... Ele tem muito conhecimento. Quem gosta mesmo da área, se quiser perguntar, ele tem muito conhecimento pra passar, mas como ela falou, ele não está preparado para dar aula para alunos do ensino médio. Igual eu falei, primeiro e segundo ano, a gente estudou isso com ele, a gente fazia, claro, ele falava de ângulo, ele falava de graus, não sei o quê, tudo bem, a gente estudava isso, só que aí chega no terceiro ano, tem o ENEM, tem aquilo, a gente chegou no terceiro ano e tá passando muita dificuldade com a nova professora, porque ela é ali ao pé da letra, é fórmula, matéria... (Grupo Focal Escola B).

E ainda fazem reverberar, no plural, as tensões da relação professor-aluno. Reconhecem as condições nas quais seus professores exercem o ofício de ensinar. Revelam as adversidades que envolvem a humana condição docente e que perpassam a também humana condição juvenil.

Marlice: Tem professor que chega e fala: "eu ganho é por cabeça..."

Marlice: "Eu não preciso tá aqui..."

Fabiano: “... vocês estando aqui, eu dando aula ou não, eu vou ganhar do mesmo jeito..."

Adriana: É, é desse jeito.

Marlice: Se eu ficar sentado aqui ou ficar explicando eu vou ganhar do mesmo jeito...

Adriana: Exatamente, isso pra mim é arrogância.

Fabiano: Tem professor também que não tá com a vida boa e chega dentro da sala descontando a raiva dele na gente.

Adriana: É. 
Fabiano: Problemas pessoais, de fora da escola.

Mediadora: É? E como é que vocês sabem que é coisa pessoal, de fora da escola?

Marlice: Uai, porque eles começam a falar, uai.

Fabiano: Já chega estressado... (Grupo Focal Escola B).

Interessante como os jovens percebem o professor contemporâneo como um sujeito da contradição, aludido por Charlot (2013) como aquele que deve enfrentar o choque entre as práticas do professor real e as injunções dirigidas ao futuro professor ideal. As falas revelam também o lugar precário que o docente da educação básica ocupa em nossa sociedade, acumulando uma trajetória errática que o obriga a passar por inúmeras escolas sem ter tempo de estabelecer um vínculo efetivo e afetivo com a instituição onde trabalha, com seus pares e tampouco com os seus alunos.

Mediadora: Teve muita troca de professor?

Livia: Teve.

Marcos: Mas tudo matéria difícil, teve três trocas...

Mediadora: No segundo ano?

Marcos: Foi.

Mediadora: Isso é ruim, né?

Marcos: É. Atrapalha.

Patricia: Acabou atrapalhando, foi ruim, porque a gente ficou praticamente dois anos mudando de professora de Português.

Livia: $\mathrm{O}$ ano passado a gente praticamente não teve aula de Português e Português é uma matéria assim... essencial.

Vários: É.

Livia: Exatamente! Porque os professores estão presentes, mas a gente não entende nada. (Grupo Focal Escola A)

O professoré também frequentemente convidado a fazer o uso de novas tecnologias em seu ambiente de trabalho, mas alega que não foi formado para isso. A "forma escolar hegemônica" (VINCENT, LAHIRE e THIN, 2001) - percebida através da disposição espacial e temporal, da enturmação - parece não conciliar com a cultura digital:

Mediadora: Como que a escola lida né, com os usos desses aparelhos, o celular, o tablet, o fone...

Gustavo: Só na teoria, na prática...

Selma: A coordenação proíbe, os professores, a maioria faz vista grossa, mas se a coordenação tá perto, finge que cumpre. 
Mediadora: E o que vocês acham disso? Dessa maneira com que eles lidam com o celular?

Selma: Eu acho um saco.

Selma: Eu acho que assim, nem é questão disso, é mais questão de... proibindo ou não, a gente faz. É, se você proíbe uma coisa que, que me ajuda, por exemplo, se eu tô fazendo o exercício e eu tô ouvindo uma música e eu consigo fazer o exercício melhor, beleza, mas tem gente que não vai né, não consegue ter essa concentração, mas celular e fone de ouvido é uma coisa pessoal cara, não interfere em nada! $\mathrm{Na}$ aula dele, no que ele tá explicando, não interfere, não interfere no que o outro aluno tá fazendo... (Grupo Focal Escola B).

A cultura midiática como instituição socializadora é uma realidade que ainda flutua no interior da escola. Nesse sentido, as relações sociais juvenis demarcadas pelos processos de destemporalização e deslocalização das aprendizagens, colidem com as dinâmicas espaçotemporais do ambiente escolar. À simultaneidade dos tempos e espaços midiáticos, os jovens aprenderam outras linguagens, desenvolveram habilidades de navegação virtual, aguçaram os sentidos. Exercer a docência nesse cenário e ainda lidar com um quadro de complexidades históricas, envolvendo questões materiais, funcionais, formativas e subjetivas da condição docente, é uma tarefa desmesurada.

\section{A EFETIVIDADE DO REM FRENTE ÀS EXPECTATIVAS DOS JOVENS}

Que sentidos têm para os jovens ir à escola? Que sentidos têm aprender na escola e em outros espaços? Estas questões são centrais na perspectiva teórica apresentada por Charlot (2000) e são consensualmente evocadas quando se trata de pensar as políticas educacionais para os jovens do ensino médio. Entretanto, há uma distância entre o nosso desejo (outro) e o deles.

Mediadora: Como é que foi, por exemplo, a entrada de vocês na área de empregabilidade?

Bruna: Bastante complicada, porque como não tinha uma estrutura boa, foi muito complicado.

Everton: É, exatamente.

Bruna: ... vamos lá, tem uma bomba aqui, vamos supor, se você não escolher, o trem arrebentava.

Everton: ... a gente chegou aqui para fazer matrícula, eles falaram: "tem essas três matérias, escolhe aí e o cara ainda com pressa, né?

Bruna: É, eu entendo porque escola é assim, tem que ter uma burocracia sim, mas eles deveriam ter informado melhor as pessoas sobre o curso pra ter uma organização melhor na escola. 
Mediadora: E essas três áreas, por exemplo, vocês sabem que o REM tem outras áreas, sabem?

Bruna: Ninguém falou nada.

Everton: É porque aqui só foi pra dar essas três porque eles acharam que era a que casava mais com a população. (Grupo Focal Escola A).

Esse diálogo retrata uma das primeiras dificuldades enfrentadas pelos jovens ao serem informados da nova organização curricular. $\mathrm{O}$ documento oficial listava 18 áreas de empregabilidade e salientava que outras ainda poderiam ser criadas. Porém, no processo de expansão do REM, diversamente do que ocorreu nas 11 escolas-piloto que iniciaram em 2012, não houve o envolvimento prévio dos docentes e alunos na definição das áreas.

Os grupos focais, que deveriam ser previamente realizados com os jovens, ocorreram somente na primeira fase, descaracterizando a proposta tal como foi concebida. O Seminário de Percurso Curricular que deveria ser realizado pelas escolas com o intuito de apresentar aos jovens as áreas de empregabilidade não ocorreu nas fases de expansão e universalização.

Grande parte dos jovens fez a escolha com pouco ou nenhum conhecimento sobre as áreas de empregabilidade e sobre o REM. Para alguns, o REM se tornou conhecido no ato da matrícula quando eram instados a "escolher" qual área de empregabilidade desejariam cursar. Outros, ao final do nono ano receberam "uma folha pra preencher" e deveriam escolher uma dentre as áreas ofertadas pela escola, justificando a escolha. Quem não a devolveu no primeiro dia de aula, não teve outra chance de manifestar seu interesse. Outros ainda iniciaram as aulas e um mês depois receberam a folha. Entre o esquecimento dos jovens e a pressa da escola, a maioria foi "encaixada" onde era possível. Há ainda o caso de quem chegou de outra escola para matricular-se numa escola do REM. Foi orientado a escolher duas áreas de interesse e acabou "caindo" inesperadamente em uma terceira área.

Lucas: Eu acho que foi é sacanagem mesmo, porque tipo assim, quem tá fazendo, quem fez o Reinventando o Ensino Médio, pra quem que é o Reinventando o Ensino Médio? Pra gente. Então quem que devia ter escolhido? A gente que é aluno!

Everton: E foi, foi o diretor que escolheu, então devia ter posto o diretor para estudar o Reinventando, ué! (Grupo Focal Escola A)

Ressalta-se ainda que, após a matrícula, muitos jovens declararam terem sido surpreendidos com trocas por outras áreas e, em alguns casos, trocas de turnos quando a área desejada não reunia número suficiente de optantes. Desse modo, os percursos formativos 
resumiram-se a um contrassenso, uma vez que o plano inicial era que estes percursos seriam construídos pelos próprios jovens com base em uma variedade de áreas de empregabilidade oferecidas pelas escolas, de modo a atender às demandas formativas e responder às reiteradas queixas ${ }^{10}$ dos jovens a propósito da falta de sentidos da escola.

Fabiano: Eu acho que foi uma ideia assim louvável da parte do governo, só que na prática é muito complicado, né? É, adequar uma escola pública com profissionais que não são da área, pra dar um ensino bem direcionado, então eu acho que o maior problema foi esse. Às vezes, o que acontecia? Tinha a aula proposta, por exemplo, eu era Comunicação, né? É, o professor chegava com uma aula proposta só que ele não sabia muito o que falar aquilo que ele estava em mente, porque sabe, eu acho que os professores devem receber uma pauta sobre o que eles devem ensinar, né, eu imagino, e aí eles não sabiam ensinar a pauta e aí era engraçado, mas a ideia é boa. (Grupo Focal Escola B)

A agudeza de suas falas revela que o peso e o valor dado às iniciativas de qualificação do ensino são constantemente avaliados, reconsiderados pelos jovens na medida de sua incorporação ao cotidiano escolar. Não é uma recusa ao ensino ofertado, mas é a evidência de que suas experiências escolares se constroem nos limites da mediocridade ou, até mesmo, da inutilidade daquilo que se ensina. Como assinalam Dubet e Martucelli (1996), na experiência escolar juvenil não existem perfis antagônicos, mas distintas maneiras de senti-la e de vivenciá-la.

Poliana: Eu acho que meio que aprimorou algumas qualidades que a gente tinha, igual quem fez comunicação aplicada, tinha muita coisa da criatividade, do... do conjunto, de trabalhar em equipe, mas alguma coisa específica assim para fazer, tipo "nossa, eu poderia fazer isso no futuro", eu acho que não (Grupo Focal Escola C).

Retomando reflexões anteriores acerca dos projetos de futuro, o lugar da escola e a pertinência dos processos de escolarização, há uma manifesta percepção de que a experiência do REM poderia terlhes ampliado o horizonte e dado outra orientação, ao oferecer um novo rumo, um possível futuro.

Para Dayrell, Leão e Reis (2011), o projeto de vida não se resume a um único destino, não é um cálculo matemático estrategicamente elaborado, mas é um plano de ação que o indivíduo se propõe a realizar e que vai se transformando, ao passo em que os jovens amadurecem, transformam seus sonhos e fantasias em objetivos alcançáveis. O contexto socioeconômico e as situações vivenciadas no presente é que darão consistência aos desejos, transformando-os em substância: “(...) falar em projeto é referir-se a uma determinada relação com o tempo, em especial o futuro, e especificamente às formas como a juventude lida com esta dimensão da realidade”. (DAYRELL, LEÃO E REIS, 2011, p.1072) 
O depoimento de Poliana confirma a relevância dos processos de escolarização no delineamento de seus projetos de futuro. Contudo, Poliana também nos diz que tudo depende da maneira como essa experiência vivida no presente (o REM) se relacionava com o passado e o futuro. Ou ainda, como a política educativa se articulava aos interesses dos jovens, suas aspirações e objetivos. Fossem eles de curto, médio ou longo prazo. Estendidos no tempo presente ou desenhados num tempo porvir.

\section{TEMPOS E CONTRATEMPOS: O REM, A ROTINA ESCOLARE AS DEMANDAS JUVENIS}

Mediadora: Eu quero saber qual que é a relação entre a experiência do Reinventando e a vivência de vocês na escola?

Patricia: Perda de tempo.

Bruna: Perda de tempo.

Fabiana: Eu acho que aquelas aulas, não foi à toa, é (...) assim, hoje por exemplo eu consigo, eu fiz TI, eu tenho uma qualidade melhor pra fazer uma planilha, uma coisa assim mais elaborada, até porque eu gostava muito do professor, ele ajudava bastante. É, mas, porém, eu acho meio irrelevante porque a gente não concluiu, véio! Eu fiquei dois anos fazendo aquilo, que eu preferia ficar mais um horário aqui esse ano de novo, já não fiquei os dois? Ficaria aqui mais esse horário esse ano de novo e terminaria o curso, entendeu? Por que ficou, o que que eu coloco no meu currículo? É, Empreendedorismo em TI incompleto? É isso que eu vou colocar ou então não vai me servir de nada? Eu fiquei um horário aqui à toa? (Grupo Focal Escola A)

Uma das questões mais evidentes no REM foi a alteração na carga horária diária. O sexto horário, marca indelével do projeto na rotina dos sujeitos da escola, foi a maneira encontrada para ampliar o tempo de permanência dos jovens na escola e a carga horária de formação, que passaria de 2.500 para 3.000 horas. No turno noturno essa integralização ocorreria através de atividades extraclasse, sob a forma de projetos.

Ambiguamente, o sexto horário tinha a sua positividade. Para alguns jovens, era bom porque estavam ali na escola para estudar a área de empregabilidade que lhes interessava e, com isso, se sentiam parte do projeto. Esses são os jovens que fazem o que gostam. Outros jovens, mesmo não havendo muitas escolhas ou tendo que adequarse ao que era oferecido, acabaram "se encontrando" naquilo que era possível, no que lhes foi apresentado como possibilidade. Esses são os que gostam do que fazem.

O diálogo abaixo entre duas jovens explicita as debilidades de ações governamentais pensadas para o outro de maneira verticalizada. Os jovens não se sentiram sujeitos ativos dos processos de mudança 
implementados. A forma como uma política pública é pensada, executada e extinta dificilmente leva em consideração as demandas de seus destinatários. A falta de compreensão das dinâmicas de implantação de uma política na prática impede-nos de entender as políticas 'por baixo' (LESSARD E CARPENTIER, 2016).

Amanda: Que tristeza! Mas fora o horário de meio dia e vinte, eu achava muito bom, eu gostava de Turismo.

Patrícia: Não, eu acho que por a gente fazer Turismo, a gente tinha que ter mais excursão.

Amanda: Não teve, e de vez em quando ela mandava a gente fazer algumas visitas... Antes tinha recurso.

Patrícia: Foi quando começou..., mas quando chegou a nossa vez... xiii...

Amanda: Acabou.

Patrícia: É que deu uma esfriada.

Amanda: Diz a Cíntia que quando começou, aí teve verba, mas aí quando chegou a nossa vez, a verba já tinha ido embora! (Grupo Focal Escola A).

Contrariamente ao que se propunha, o processo de expansão do REM ocorreu de maneira desacertada, tal como ilustram os excertos das falas dos jovens. E tal como começou, terminou. Em 2015, na mudança de governo estadual, uma das primeiras ações foi a extinção do REM. Assim, do nada, como disseram os jovens. E se dissiparam também as promessas de uma certificação "quase" profissional, de um currículo diferenciado ou "de uma coisa a mais pra sair do ensino médio", como relata um dos jovens entrevistados.

Mediadora: Entendi. É, qual que era a expectativa de vocês quando começou, assim? Tipo, chegaram com a notícia...

Lucas: Ah, era uma coisa a mais pra sair do ensino médio, né? Aprender uma coisa...

Bruna: É, uma experiência a mais.

Mediadora: Isso que vocês esperavam?

Everton: Acabou que foi em vão!

Patrícia: Ficamos tudo iludido!

Lívia: Até porque quando chegou, era muito bom assim, todo mundo participava na moral, porque tinha os recursos, tinha tudo, mas... porque a gente estava no nono ano, antiga oitava série, aí quando a gente foi pro primeiro já não teve mais tanta coisa, quando a gente foi pra segundo então...

Luciana: Muito menos.

Bruna: ...não tinha nada.

Patrícia: E esse ano, e esse ano que a gente tá no terceiro, o governo cortou o projeto, então os dois anos que a gente fez ficou perdido.

Everton: Ficamos até meio dia e vinte à toa! (Grupo Focal Escola A). 
As falas dos jovens nos remetem aos princípios que orientaram a reformulação curricular, vividas pelos sujeitos em suas potencialidades e limitações. A busca por uma identidade própria e significação para uma etapa de ensino que parece um eterno vir a ser e carece de sentidos é diligentemente empreendida por eles. O prosseguimento dos estudos é percebido em seus diálogos como um direito e um horizonte. E a tão desejada e bem-recebida empregabilidade, que forneceria instrumentos para a inserção no mundo do trabalho, foi onde mais se explicitaram as contradições da política pública na experiência escolar dos jovens.

Amanda: Eu tive que sair do emprego porque não dava pra conciliar os horários, então foi entre o emprego e esse Reinventando, eu acreditava né, gostei da ideia, aí eu deixei o emprego pelo Reinventando, aí era como os professores falavam: "vocês são os cobaias, o governo implantou isso aí, nós vamos colocar pra ver como que vai progredir essa ideia" e muita gente acreditava, tanto que quando acabou muita gente falou: "porque que acabou? Eu estava interessado, eu estava...", muita gente tirava proveito, muita gente gostava e acabou.

Lívia: Foi como você dar um doce pra uma criança e simplesmente depois tomar. Lucas: É e eles não falaram nada com a gente.

Amanda: Não teve uma informação que ia tirar, nem nada, simplesmente tiraram o programa, da mesma forma que implantaram. (Grupo Focal Escola A).

\section{RECAPITULANDO...}

A implantação do REM nas escolas pesquisadas provocou sensíveis alterações não apenas no cotidiano dos jovens e também no trabalho e na rotina funcional dos docentes. Embora se pretendesse gradativa, a expansão do REM foi arduamente sentida pelos sujeitos da escola. Ainda que revelassem representações positivas sobre o REM, os jovens deixaram entrever que vivenciam formas frágeis e insuficientes de escolarização. Há, portanto, uma diversidade de representações construídas pelos próprios jovens sobre os sentidos dessa política educativa, os significados da escolarização proposta, a trajetória escolar, a repercussão na vida familiar, no trabalho ou nos projetos de futuro.

Desse modo, é inequívoco afirmar que as vicissitudes da implementação do REM atravessaram as formas de relacionar-se com a escola e amplificaram a permanente tensão vivida pelos jovens, que se situa entre uma apropriação instrumental da escolarização e uma perspectiva de voltar-se para a individualidade. É que o desejo de estudar, escolarizar-se e aprender parece esbarrar constantemente na necessidade de ter projetos de vida, perspectivas de futuro, emprego, 
uma vaga na universidade, um lugar no mundo. Mantém-se ativada uma aparente contradição entre estudar para subir na vida, estudar o que se deseja ou fazer o que se quer.

Essa aparente contradição fica mais estampada quando os jovens falam de suas expectativas quanto ao futuro, de sonhos e desejos. Concomitantemente, falam das dúvidas, das hesitações, das dificuldades, das necessidades e das impossibilidades. Mediante isso, assumem o presente estendido como área temporal na qual estabelecem projetos de curto prazo. Segundo Leccardi (2005), os projetos que se expressam sob arcos temporais mínimos são facilmente maleáveis. Para alguns jovens, são uma forma de reagir às inquietudes provocadas pela ideia de futuro e, para outros, são formas projetivas concretas de apoderar-se do seu próprio tempo biográfico.

Leccardi (2005) declara que esta via mediana encontrada pelos jovens que vivem em condições sociais de grande insegurança e de risco "[...] parece especialmente atraente porque, enquanto não impede de todo uma projeção no futuro por meio do projeto, está em sintonia com a orientação maleável que se tornou necessária numa época na qual os processos de mudança são rápidos e frequentemente imprevisíveis" (p. 53).

O olhar discente sobre o REM tende a nos dizer que, na vivência cotidiana da maioria dos jovens alunos entrevistados, o projeto tinha potencialidades, mas redundou-se à oferta de um sexto horário. Oferta essa que, no caso de jovens trabalhadores matriculados no período diurno, inviabilizava ou dificultava sobremaneira a articulação escola e trabalho. A implementação do REM levou muitos alunos à troca de escolas ou à perda de empregos também pela dificuldade de compatibilizar o sexto horário com horário de almoço - que era oferecido em pouquíssimas escolas, dada as condições estruturais dos estabelecimentos de ensino - e o horário de entrada no trabalho.

Para os jovens do ensino noturno esse "sexto horário" nem chegou a existir. Isso significa que se encontraram, mais uma vez e em razão das suas necessidades de buscar trabalho, impedidos do efetivo acesso às políticas educacionais proporcionadas aos jovens do ensino diurno. A impossibilidade de integrar o sexto horário à rotina escolar noturna, levou os gestores do ensino a articular outra maneira de ofertar os componentes curriculares das áreas de empregabilidade que, na prática, não funcionou nas escolas. Nesse caso, o REM funcionaria no formato de projetos de estudos, com carga horária que deveria ser complementada aos sábados. Tanto mais quanto menos é uma frase que poderia sintetizar as condições desiguais de acesso ao REM para muitos jovens. 
Em outras palavras, se no REM havia essa prerrogativa da inserção múltipla no mercado de trabalho ou de qualificação para o trabalho, desconsiderou-se que o trabalho já era uma realidade para $32,3 \%$ dos jovens pesquisados. E, paradoxalmente, para muitos desses, o REM significava efetivamente um elo entre os dois mundos, escola e trabalho.

Resta-nos dizer que a implementação do REM afetou, distintamente, a todos. Os jovens, docentes, coordenadores pedagógicos e gestores manifestaram uma ambivalência de sentimentos. Com entusiasmo e otimismo, denotavam a assertividade do projeto. Com descrença e tristeza traduziram o descontentamento com o processo de implantação de uma política que, como outras historicamente conhecidas, foi praticamente arremessada para o interior das escolas. Sob o entendimento de que é preciso elevar os índices de proficiência/ desempenho de nossos jovens do ensino médio e a pretexto de qualificá-los para o mercado de trabalho, o REM foi instituído à revelia das especificidades de cada contexto escolar e das condições singulares de seus sujeitos.

\section{REFERÊNCIAS}

ABAD, M. Crítica política das políticas de juventude. In: FREITAS, M. V.; PAPA, F. de C. (org.). Políticas públicas: juventude em pauta. São Paulo: Cortez; Ação Educativa; Fundação Friedrich Ebert, p. 13-32, 2003.

ABRAMO, H. W. Considerações sobre a tematização social da juventude no Brasil. Revista Brasileira de Educação, Rio de Janeiro, n. 05, p. 25-36, agosto 1997.

ABRAMO, H. W. Condição juvenil no Brasil contemporâneo. In: ABRAMO, H. W. e BRANCO, P. P. M. Retratos da juventude brasileira: análises de uma pesquisa nacional. São Paulo: Instituto Cidadania/Fundação Perseu Abramo, p. 37-72, 2005.

ALVES, F.; FRANCO, C.; RIBEIRO, L. C. Q. Segregação residencial e desigualdade escolar no Rio de Janeiro. In: RIBEIRO, L. C. Q.; KAZTMAN, R. (ed.). A cidade contra a escola: segregação urbana e desigualdades educacionais em grandes cidades da América Latina. Rio de Janeiro: Letra Capital, p. 91-11, 2008.

BATISTA, A. A. G.; CARVALHO-SILVA, H. H. Família, escola, território vulnerável. São Paulo: CENPEC, 2013.

CHARLOT, B. O professor na sociedade contemporânea: um trabalhador da contradição. Da relação com o saber às práticas educativas. São Paulo: Cortez, 2013.

CHARLOT, B. Os jovens e o saber: perspectivas mundiais. Porto Alegre: Artes Médicas. 2001.

CHARLOT, B. Da relação com o saber. Elementos para uma teoria. Porto Alegre: Artes Médicas Sul, 2000.

DAYRELL, J. A escola como espaço sócio-cultural. In: DAYRELL, J. (org.) Múltiplos olhares sobre educação e cultura. Belo Horizonte, UFMG, p. 136-161, 2001. 
DAYRELL, J.; LEÃO, G. e REIS, J. B. Jovens olhares sobre a escola do ensino médio. Cadernos CEDES, Campinas, v. 31, n. 84, p. 253-273, ago. 2011.

DUBET, F. e MARTUCELLI, D. À l'école: sociologie de l'expériences ecolaire. Paris: Éditions Du Seuil, 1996.

ELIAS, N. Sobre o tempo. Rio de Janeiro: Jorge Zahar Ed., 1998.

INSTITUTO NACIONAL DE PESQUISAS EDUCACIONAIS ANISIO TEIXEIRA. Censo Escolar da Educação Básica 2016. Disponível em: http://portal.inep.gov.br/ web/guest/sinopses-estatisticas-da-educacao-basica. Acesso em: 05 mar. 2017.

KOLINSKI, M. C., ALVES, F. Novos olhares para as desigualdades de oportunidades educacionais: a segregação residencial e a relação favela asfalto no contexto carioca. Educação e Sociedade, Campinas, v. 33, n. 120, p. 805-831, jul.-set. 2012.

LECCARDI, C. Por um novo significado do futuro: mudança social, jovens e tempo. Tempo Social. Revista de Sociologia da USP, São Paulo, v. 17, n. 2, p. 35-57, 2005.

LESSARD, C.; CARPENTIER, A. Políticas Educativas: aplicação na prática. Petrópolis, RJ: Vozes, 2016.

MALSCHITZKY, N. A importância da orientação de carreira na empregabilidade. Rev. FAE, Curitiba, v.15, n.1, p.150-165, jan./jun. 2012.

MARGULIS. M. e URRESTI, M. La construcción social de la condición de juventud. In: LAVERDE, M. C. et al. (ed.). "Viviendo a toda": jóvenes, territórios, y nuevas sensibilidades. Bogotá: Siglo Del Hombre/DIUC Universidade Central, p. 3-21, 1998.

MINARELLI, J. A. Empregabilidade: o caminho das pedras. São Paulo: Gente, 1995.

OLIVEIRA, M. A. G. O novo mercado de trabalho: guia para iniciantes e sobreviventes. Rio de Janeiro: SENAC, 2000.

RIBEIRO, L. C. Q.; KOSLINSKI, M. C. Fronteiras urbanas da democratização das oportunidades educacionais: o caso do Rio de Janeiro. In: RIBEIRO, L. C. Q. et al. (org.). Desigualdades urbanas, desigualdades escolares. Rio de Janeiro: Letra Capital, p. 121-153, 2010.

SALATA, A. R. Estudar x trabalhar: as influências do local de moradia sobre as escolhas dos jovens no município do Rio de Janeiro. 2010. Dissertação (Mestrado em Sociologia e Antropologia) - Instituto de Filosofia e Ciências Sociais, Universidade Federal do Rio de Janeiro, Rio de Janeiro.

SARTI, C. A família como espelho: um estudo sobre a moral dos pobres. Campinas-SP: Autores Associados, 1996.

SECRETARIA DE ESTADO DA EDUCAÇÃO DE MINAS GERAIS. Educação em Minas Gerais. Educacenso 2015. Disponível em: https://www.educacao.mg.gov.br/ images/documentos/Educação\%20em\%20Minas\%20Gerais\%20-\%20Educacenso \%20 2015.pdf. Acesso em: 09 mar. 2015.

SECRETARIA DE ESTADO DA EDUCAÇÃO DE MINAS GERAIS. Reinventando o Ensino Médio. 2012. Disponível em: <https://www.educacao.mg.gov.br/images/stories/ publicacoes/reinventando-o-ensino-medio.pdf>. Acesso em: 9 jan. 2014.

SPOSITO, M. Algumas reflexões e muitas indagações sobre as relações entre juventude e escola no Brasil. In: ABRAMO, H. W. e BRANCO, P. P. M. Retratos da juventude 
brasileira:análises de uma pesquisa nacional. São Paulo: Instituto Cidadania; Fundação Perseu Abramo, p. 129-148, 2005.

VINCENT, G.; LAHIRE, B. e THIN, D. Sobre a história e a teoria da forma escolar. Educação em Revista, Belo Horizonte, n.33, jun./2001.

\section{NOTAS}

${ }^{1} \mathrm{O}$ artigo é um recorte da pesquisa Juventudes e Escola: diagnóstico da condição juvenil e do Ensino Médio na Região Metropolitana de Belo Horiz̧onte- Minas Gerais, financiada pela Fundação de Amparo à Pesquisa do Estado de Minas Gerais em parceria com a CAPES (APQ-03474-12, Edital 13/2012, Acordo para Cooperação Técnica e Científica Capes/FAPEMIG), a quem agradecemos o apoio recebido.

${ }^{2}$ Doravante será chamado REM.

${ }^{3}$ A escolha da Regional Norte não ocorreu por acaso. A Resolução n' 002, de 28/11/11 e o caderno "Territórios Educativos em Belo Horizonte - Planejamento Integrado do Sistema Público de Educação Básica" já explicitavam a existência de um termo de cooperação técnica entre a Secretaria Municipal de Educação de Belo Horizonte e a Secretaria de Estado de Educação de Minas Gerais que definiam a Região Norte de Belo Horizonte como Território Educativo para uma atuação em rede. Baseando-se em: a) existência de Plano Diretor da Região Norte e de Expansão do Vetor Norte; b) altos índices de vulnerabilidade da região; c) altos índices de desigualdade social na região; d) grande diversidade cultural; e) ocupação territorial desordenada até então e f) tendência de crescimento populacional, a Região Norte era o território propício à implementação de um projeto piloto educacional. Para o monitoramento e avaliação do processo de implementação do projeto, a Secretaria de Estado da Educação contava com o apoio do Escritório de Prioridades Estratégicas, órgão diretamente vinculado ao Governo de Minas e que tinha como missão cooperar com as unidades setoriais para o alcance de suas metas prioritárias. Como atribuições, o Escritório deveria contribuir na definição e execução de projetos estratégicos, assumindo papel colaborador junto à Administração Pública por meio da análise e gestão de informações e da alocação de profissionais qualificados para a execução dos projetos.

${ }^{4}$ As resoluções que orientaram a implantação do REM foram: Resolução SEE/MG 2.030 de 20 de janeiro de 2012, Resolução SEE/MG 225102 de janeiro de 2013, e Resolução SEE/ MG 2486, 20 de dezembro de 2013.

${ }^{5}$ Ao escolher as abordagens e os instrumentos metodológicos citados, orientamo-nos pelos procedimentos éticos estabelecidos para a pesquisa científica em Ciências Humanas. $\mathrm{Na}$ coleta dos dados quantitativos foram utilizados questionários autoaplicáveis, preservando o anonimato dos jovens e das escolas. Nos grupos focais, mantivemos o anonimato dos jovens e de suas respectivas escolas.

${ }^{6} \mathrm{~A}$ fim de preservar o anonimato das escolas, este trabalho fará uso das letras A, B e C para identificá-las. Cabe ressaltar que tais escolas constituíam o grupo de escolas da fase de expansão do REM.

${ }^{7}$ Empregabilidade (employability) é a capacidade de o indivíduo manter-se no emprego ou reinserir-se no mercado de trabalho. Tal competência constitui-se a partir de um conjunto de conhecimento, habilidades e comportamentos que possibilitam ao trabalhador ser polivalente, ajustando-se ao setor produtivo e de serviços. O conceito emerge na Inglaterra 
no início de 1990, para referir-se aos profissionais de nível superior e altamente qualificados que, uma vez demitidos de seus postos de trabalho, buscavam reinserção laboral. Com a relativização da crise do emprego, o termo faz referência também às parcelas da população com baixa escolaridade e poucas chances de disputa no mercado de trabalho. No início dos anos 1990, as agências multilaterais tais como Banco Mundial e Comissão Econômica para a América Latina e o Caribe (Cepal), o empresariado e o Ministério do Trabalho lançam mão desse conceito para articular educação e melhoria na qualificação dos trabalhadores. (MINARELLI, 1995; OLIVEIRA, 2000; MALSCHITZKY, 2012). É nessa perspectiva que as atividades de qualificação profissional seriam, posteriormente, articuladas à educação básica. Enquanto a escola assume a formação do profissional para a realidade do desemprego, esse mesmo profissional é quem deve cuidar do seu aperfeiçoamento, tenha conseguido ou não um posto de trabalho. A capacidade para ter emprego, manter-se nele, competir por quaisquer postos de trabalho passa a ser autonomamente governada pelo próprio indivíduo.

${ }^{8}$ Em Minas Gerais, o Índice de Desenvolvimento da Educação Básica (IDEB) no ensino médio da rede estadual era de 3,7 em 2011, baixando ligeiramente para 3,6 em 2013 e retornando a 3,7 em 2015. A meta do estado para 2015 era 4,4 (INEP, 2016).

${ }^{9}$ Nesta seção, as vozes dos jovens emergem dos excertos extraídos de grupos focais realizados em três escolas. Seguindo o protocolo ético da pesquisa, os nomes aqui presentes foram substituídos por outros nomes, a fim de preservar a identidade dos sujeitos.

${ }^{10}$ Tais queixas surgiram nos grupos focais realizados em algumas das escolas-piloto e foram corroboradas por pesquisas citadas em documentos da Secretaria Estadual da EducaçãoMG. Referem-se, sobretudo, à ausência de uma sólida preparação para a continuidade dos estudos, à dissociação entre escola, mundo do trabalho e a própria vida, bem como à inflexibilidade curricular, resumindo-se à falta de interesse nos estudos.

Submetido: $17 / 07 / 2017$

Aprovado: 16/02/2018

Contato:

Universidade Federal de Minas Gerais (UFMG) FaE - Faculdade de Educação Av. Presidente Antônio Carlos, no 6627 - Pampulha, Belo Horizonte |MG | Brasil

CEP 31.270-901 